\title{
SUSTAINABLE DEVELOPMENT FRAMEWORK OF HISTORICAL CITIES. A CASE STUDY: CITY OF SOLTANIYEH.IRAN
}

\author{
Morteza OJAGHLOU (D) \\ Department of Architecture, Qazvin Branch, Islamic Azad University, Qazvin, Iran
}

Received 20 March 2020; accepted 11 June 2020

\begin{abstract}
Unfortunately, the architecture and urbanization of the Iranian cities, especially the traditional Iranian cities in the present era, are in many cases in contrast to the historical, social, and cultural background of these cities. In this study, architectural design in small historical cities such as Soltaniyeh has been explored to achieve a conceptual and sustainable architecture through a research-based library approach inference. Achieving the principles of architectural design in the historic city of Soltaniyeh. Iran is the main concern of this research. Therefore, to reach an integrated design process, previous studies and projects were examined and analyzed and the obtained data and principles, including historical, cultural, social, natural, climate, were in the design process of the real project. As a final result of this study, the integrated design process of these parameters is presented as a process of architectural design in small historical cities such as Soltaniyeh.
\end{abstract}

Keywords: sustainable development, traditional city, contextual architecture, integrated design process, city of Soltaniyeh.

\section{Introduction}

Sustainable development and related concerns are the subject of many branches of science and affect almost all aspects of human life (Lele, 1991). Paying attention to Sustainable development has a direct relationship with the number of difficulties that could happen in human societies (Mitchell, 1996). It should be noted that although the experience of many of the global problems and crises that many countries in the world have faced during their development, lack of sufficient local studies made those experiences deficient in other societies and this is the main reason for repeating common problems with a different appearance. In Iran, many of the sustainable development studies, are related to past and traditional Iranian societies (Sharifi \& Akito, 2016; Assari et al., 2011) while Research related to urban problems and issues are related to the present era. Architecture and urbanization are considered as an important branch of the subcategory of the concept of sustainable development (Bennetts et al., 2003). Utilizing architecture and urbanization for sustainable city development in many countries, including Berlin (Ahlfeldt \& Wolfgang, 2009) Beijing (Li et al., 2005) Dubai (Ponzini, 2011) have been carried out. The sustainable development of these cities has been based on the planning of architecture and urbanization, which has been used for urban development and tourism development as the main factor for the development of these cities. The interrelationship between architecture and sustainable urban development is an issue that has been most recently seen in the traditional Iranian architecture and urbanization which, elements of the traditional Iranian cities, as architectural units, have met the cultural, social, and economic needs of the city. Unfortunately, the development plan of many cities in our country Iran is based on industrial development, and although many of the terms of development are sustainable were used but, in practice, industrial development is considered as the ultimate solution to the development of Iranian cities. Due to the various dimensions of the concept of sustainability and the impact on various aspects of science, often no attention is given to the concept of integration and often the cases of one aspect of the various aspects of sustainability prevail. In architecture and urbanization, climate-related topics and energy consumption are the keys to sustainable architecture and urban research. Historic cities are not only the old buildings of these cities, but the city is mainly the heir to the cultural, social, architectural, and urban aspects of their history. Therefore, the traditional architecture and urbanization of these cities reflect the same aspects that unfortunately, in the architecture and urbanization of the present day, no attention is paid to

${ }^{*}$ Corresponding author. E-mail: morteza.ojaqlu@gmail.com 
this heritage. The development of these cities by architectural planning and town planning requires that, as in the past, integrated attention to the formation of architecture and urbanization based on local needs. Therefore, the integrated approach to the concept of sustainability in the design of architecture and urban planning for sustainable development is the main goal of this research. The city of Soltaniyeh as one of the most important historic cities of Iran, despite high potential of historical and cultural significance, not using these capabilities in the development of this city, and the construction of various factories, including the tobacco factory, is used for the development of this city. The city's architecture and urbanization have not only solved the problems of the city but in many cases, it has been a problem for the people of this city. So, in this study, we focus on Soltaniyeh's sustainable development issues through architectural planning. The main question of this study is how small towns such as Soltaniyeh, Iran can reach sustainable development without harming the environment, culture, and social conditions of these cities.

\section{Methodology}

The research methodology is divided into three sections. In the first step, using the library method, the theoretical aspect of the concepts introduced, using the authoritative internal and external resources. In the second step, local impressions and interviews are carried out by distributing the questionnaire, interviewing the native people, and taking the data inductively using a descriptive-analytic research method. The third step of this study, using the simulation software namely Ecotect 2011 is used to analyze and present a climate-based solution in the climate sustainability sector. Finally, the data from the previous sections are discussed and in the deductive method, an integrated design methodology in the city of Soltanayeh with the aim of sustainable development is discussed.

\section{Literature review}

\subsection{Contextual architecture}

In the past decade, contextual architecture has expanded widely in cities, especially in historic cities (Levi, 2005; Kirby \& Antony, 2010). As noted in the introduction section, traditional architecture and urbanization reflect the cultural, social, economic, and climatic conditions of their cities. Traditionally, traditional architecture and urbanization met their needs and address these requirements perfectly. Maryam Gharouri al-Khwansari, in a study entitled "From Traditional to Contemporary Neighborhood," explores ways to revive local identity in contemporary urban spaces (Gharouri al-Khwansari, 2014).

In this research, inspired by the characteristics of the traditional neighborhood and considering the specific conditions and needs of contemporary residential areas, the main opportunities and solutions for restoring the identity of the neighborhoods and strengthening their stability based on the SWOT analytical tables, thirteen solutions in five main categories by And a proper connection with the city were presented including relative self-sufficiency, physical organization, popularization and strengthening of the sense of human belonging. In the process of explaining solutions to the issue of flexibility and the two-dimensional essence of contemporary neighborhoods, because of having some urban characteristics, while taking local dimensions, they are linked to the general spirit of the traditional neighborhoods, and on the other hand, it fits with living conditions. From the results of this research, it can be noted that the provision of local people's needs by local architecture and urbanization is one of the main factors behind the formation of the identity of the traditional neighborhoods, which, unfortunately, has been neglected in the present era. (Gharouri al-Khwansari, 2014). In the year 2016, a study conducted in the traditional neighborhood of Zanjan traditional market that the results of this research, conducted by field inquiry, showed the Zanjan traditional market's impact on strengthening neighborliness through the establishment of controlled access in these neighborhoods as well as the role of this traditional market in promoting the level The response of the green areas of Zanjan Square to the objective and subjective needs of the people. The results prove that the main factor of the local ownership of these neighborhoods is the factors of dependence caused by Zanjan's traditional market (Ojaghlou \& GHasemlou, 2016).

\subsection{Sustainable development}

In 1987, the Brundtland Commission published a report entitled "Our Common Future", which sought to establish a link between economic development and environmental sustainability. This report presents the definition of sustainable development, which has been accepted as the dominant substitute for development. Sustainable Development "is a development that addresses current needs without jeopardizing the capabilities and resources of the next generation" (Brundtland et al., 1987). Despite, the general and ambiguous definition of this commission, but the implementation of the suggestion guarantees the maintenance and provision of resources, both environmentally and organizationally, for future generations. The ultimate goal of sustainable development is to maintain various human and inhuman resources over time, with the same attitude to current consumption and future generations. This attitude created different subcategories for the concept of sustainability, including social sustainability, cultural sustainability, economic sustainability, environmental sustainability (Sen, 2013).

\subsection{Cultural sustainability}

The concept of sustainability and cultural issues are mainly based on the behavior of people with each other (Kim et al., 2004; Eleftheriadou, 2010; García \& Katarina, 2012). The heritage of people's behavior, through all times and history, is the native culture of each region. According to 
the definition of the Brundtland Commission, the preservation of cultural resources for future generations is an example of cultural sustainability (Ferretti et al., 2014).

Based on the aim and purpose of the research, cultural sustainability occurs in the architectural space to the emergence and appearance of human behavior and it will be strengthened when the place attachment of individual increases and the desired behaviors would be repeated (Horlings, 2015; Cheng \& Homer, 2015). So local culture can be embodied in the functions of local architecture. Sasan Salehi Milani and Maryam Mohammadi in a paper titled "Objectives and Indices for Realizing Cultural Sustainability" carried out a comparative study of cultural planning in the countries of Canada and the United States and finally adopt the results of the survey to the conditions of Tehran. The results of the surveys show that the focus and objectives of cultural planning in the Canadian and American examples emphasize the realization of the goals of cultural sustainability. Since the focus on culture is the most important aspect of planning, the importance of paying attention to it in the cultural planning of Tehran is also sought to achieve cultural stability. In this regard, it is essential for the municipality of Tehran, as an executive organization, to consider the sustainability approach and indicators for achieving cultural sustainability with a global and local perspective (Salehi Milani \& Mohammadi, 2010). Elham Vaqifi and Mansur Haghighatian in a study entitled "Investigating the Impact of Cultural Capital (Institutional Dimension) on Environmental Social Behaviors with the Sustainable Urban Development Approach (Case Study: Shiraz City)" to assess social-environmental behaviors to understand the impact of cultural capital and dimensions. It focuses on environmental social behaviors in sustainable urban development. The results of this research demonstrate that there is a significant relationship between sex, socio-economic status, marital status, and social behaviors of the environment, and the relationship between cultural capital (institutionalized dimension) and social behavior of the environment is confirmed (Vaqefi \& Haghighatian, 2014).

$\mathrm{Xu}$ and Jie considered the importance of cultural activities in shaping the status of Chinese and Western tourists in China, and the results showed that despite the spatial belonging is a prerequisite for determining destinations, but its impact is less than the satisfaction of tourism. Besides, the involvement of tourists with the perimeter environment, satisfaction, attractiveness, and motivation in determining the destination of tourists is important. The estimated model differences between Western and Chinese examples can be attributed to cultural differences $(\mathrm{Xu}$ \& Jie, 2016).

\subsection{Social sustainability}

In the previous sections, it has been pointed out that when it comes to sustainability in the field of architecture, it is often a matter of climate sustainability. While the relationship between architecture and its perimeter space is evident in the social space, it has its problems that can be considered in the field of social sustainability. The relationship between architectural space and its social environment has been scrutinized in many studies (Romero et al., 2015; Andersen \& Per, 2017; Harun et al., 2014). Social sustainability and the urban environment and its related infrastructures are highly interconnected, and meeting the needs of the community can create a mental relationship between people and their peripheral physical environment. Mahsa Abdollahzadeh and their colleagues have studied the dimensions of social sustainability in the traditional Sang-Siah Shiraz neighborhood. The results of this study show that introversion, observance of privacy and structural hierarchy in the Sang-Siah Community, on the one hand, physical and social diversity in the neighborhood, the appropriate scale, the existence of different contexts, the levels of social interactions, public spaces, and factors of identity, on the other hand, were the key factors in achieving social sustainability in the neighborhood (Abdollahzadeh et al., 2013). Ismail Zarghami, in a study entitled "The Principles of Social Stability of Residential Complexes in Iranian-Islamic Cities" in 2010, studies the conditions of social sustainability in residential complexes. This research is aimed at discovering the principles of stability and the relationship between these principles from the perspective of the community of scholars. Finally, the theoretical foundations of the stability of residential complexes are determined. This article, by comparing it with external reality, achieves practical principles, and architectural solutions (Zarghami, 2010). Mitra Ghafourian and his colleagues in 2017 recognize the components of social sustainability and its role in increasing social interactions in residential complexes as a small urban scale. This article is aimed at recognizing the effects of sustainability components on the social dimension of housing, participation, and increasing social interactions in urban life. The results show that the components of participation, identity, sense of belonging and security respectively have the most impact on increasing social interactions among inhabitants of residential complexes, and from two groups of individual and social factors defining social interactions, social factors as the most effective The factor is known to increase social interactions (Ghafourian et al., 2017).

\subsection{Climate sustainability}

The concept of sustainability in architecture is more about the aspects of energy and fossil fuels, and much research has been done in this regard.

Consumption and energy crisis in recent years has been one of the important issues in the field of architecture and urbanization around the world, and extensive studies have been conducted to improve the ecological conditions of architecture and urbanization. The scope of studies required a summary of these studies to be presented in Table 1. 
Table 1. Summary table of climate sustainability studies

\begin{tabular}{|c|c|c|c|}
\hline Authors & Field of study & Study descriptions & Results \\
\hline (Ochoa \& Capeluto, 2009) & energy consumption & $\begin{array}{l}\text { Measuring, reviewing and } \\
\text { presenting the Smart façade via } \\
\text { energy Plus software }\end{array}$ & $\begin{array}{l}1-\text { A method is suggested as a design } \\
\text { method for smart façade } \\
2 \text { - Simulation validation is done }\end{array}$ \\
\hline (Bodach et al., 2016) & $\begin{array}{l}\text { Energy-efficient } \\
\text { solutions for } \\
\text { architectural design }\end{array}$ & $\begin{array}{l}\text { Propose architectural energy } \\
\text { solutions for hotel design }\end{array}$ & $\begin{array}{l}\text { Integrated guideline for the energy- } \\
\text { efficient building is proposed (In Nepal) }\end{array}$ \\
\hline (Attia et al., 2012) & Simulation of energy & $\begin{array}{l}\text { Different forms of concepts have } \\
\text { been simulated and the most } \\
\text { optimal form has been presented. }\end{array}$ & $\begin{array}{l}1 \text { - Simulation-based tool for early } \\
\text { design of zero energy buildings in Egypt } \\
2 \text { - Sensitivity analysis is incorporated to } \\
\text { inform design prior to decision making } \\
3 \text { - Strength and limitations and are } \\
\text { identified and future improvements are } \\
\text { suggested }\end{array}$ \\
\hline $\begin{array}{l}\text { (Ojaghlou \& Khakzand, } \\
\text { 2017) }\end{array}$ & $\begin{array}{l}\text { Outdoor thermal } \\
\text { comfort }\end{array}$ & $\begin{array}{l}\text { Investigating and proposing } \\
\text { optimal central courtyard in two } \\
\text { hot and dry climates and Iran }\end{array}$ & $\begin{array}{l}1 \text { - Integration design with green spaces } \\
\text { is suggested } \\
2-\text { Effect of solar radiation on outdoor } \\
\text { activities is proven }\end{array}$ \\
\hline $\begin{array}{l}\text { (Hasehzadeh Haseh et al., } \\
\text { 2018) }\end{array}$ & $\begin{array}{l}\text { Outdoor thermal } \\
\text { comfort }\end{array}$ & $\begin{array}{l}\text { Optimal central courtyard study } \\
\text { in the hot and dry climate of } \\
\text { Isfahan }\end{array}$ & $\begin{array}{l}1-\text { The integrated design process is } \\
\text { given reaching outdoor thermal comfort }\end{array}$ \\
\hline $\begin{array}{l}\text { (Ojaghloo \& Khakzand, } \\
\text { 2019) }\end{array}$ & $\begin{array}{l}\text { Outdoor thermal } \\
\text { comfort }\end{array}$ & $\begin{array}{l}\text { Investigating and analyzing green } \\
\text { space on campus on thermal } \\
\text { stress }\end{array}$ & $\begin{array}{l}1 \text { - Effect of greenery on outdoor } \\
\text { positive activities is proven } \\
2 \text { - Integration in the design method is } \\
\text { suggested }\end{array}$ \\
\hline (Vard et al., 2019) & Thermal Features & $\begin{array}{l}\text { The thermal characteristic of } \\
\text { open and semi-open spaces } \\
\text { was presented in the climate of } \\
\text { Tehran.Iran }\end{array}$ & $\begin{array}{l}1 \text { - Effect of semi-outdoor spaces on } \\
\text { positive outdoor activities is proven } \\
2 \text { - Positive effect integrated green spaces } \\
\text { with buildings is proven }\end{array}$ \\
\hline
\end{tabular}

\section{City of study (Soltaniyeh.Zanjan.Iran)}

Zanjan is located in northwestern part of Iran and its geographical location is described in Figure 1. Soltaniyeh is located in the city of Zanjan.Iran (36.4358 north, 48.7920 east). This traditional city of Soltaniyeh is very important because of its historical background (the historical capital of the Ilkhan dynasty). The monument and Soltaniyeh dome are the largest and most magnificent buildings in Iran's traditional architecture. Soltaniyeh is one of the most prominent achievements of the traditional Iranian architecture (Iranians) and a memorial in the architecture of the Islamic period.

\section{Discussion}

\subsection{Design process}

Architectural design in the historical context has many challenges due to the period and scope of the people's mental relationship with the context of design. The acceptability and acceptance of the existence of other buildings and complexes in the context of the historical context are very important in terms of its social and cultural implications. The city of Soltaniyeh and its adjacent grasslands are so important to the people that the one-dimensional look at the design in this area is causing dissatisfaction and disrespect among the people. Therefore, considering the importance of the design framework, the need for an

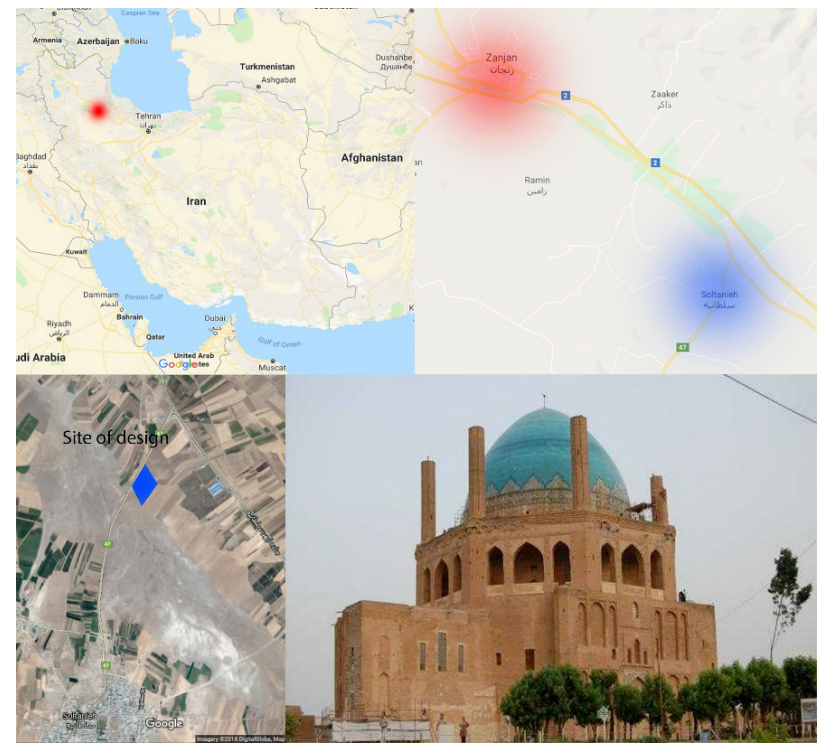

Figure 1. Location of Soltaniyeh

integrated approach to the parameters affecting the design, whether historical, natural, etc., is more evident in this design. Therefore, the explanation of the effective factors of design in the first steps of design is of great importance. Based on the Figure 2, in the first step of design, is to examine and determine the determinant factors of the architectural design. 


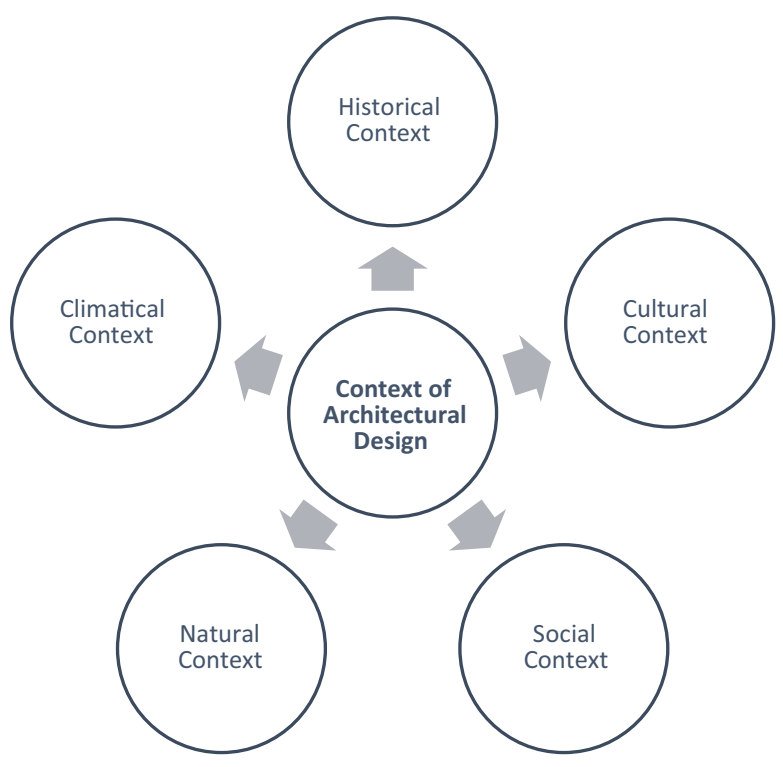

Figure 2. The differents contexts of the architectural design

\subsection{Historical context of architectural design}

The site of design is near the natural Soltaniyeh natural grass and the Soltaniyeh Dome, therefore three levels of juxtaposition is indicated in the Figure 3 and local geographical position of the existing valuable proximities are indicated in Figure 4.

The natural and historical context will cause the least intrusion with constructional structures, and somewhat distant distances will prevent approaches such as using underground space, and on the other hand, In addition to the sight of Soltaniyeh dome and grassland, according to the Figure 5, there is another view to the site from the upper porch of the dome to the site, which makes the overall geometry of the site affected in terms of plan and airspace.

There are four-part patterns that exist in Soltaniyeh's historic citadel. On the other hand, the natural identity of Grassland of Soltaniyeh, in general, provides a model for maximum interaction of the Designed buildings of this site with its adjacent nature. On the other hand, seeing from the porch of Soltaniyeh dome to the 800-year-old platform causes the pattern of the four Persian gardens as the basis and the overall structure of the site plan should be considered. From a grand metropolitan perspective, the two monuments and valuable complex of Rabe-Rashidi and Chalabi Oghli as an Indicative and common building of Ilkhani period strengthen the use of the four-part pattern in the form of the Persian garden. The Rabe-Rashidi and Chalabi Oghli and their four-part patterns are shown in Figure 6 and Figure 7.

In the next step, the location of the buildings in this site is important, which can be verified at based on the below list:

1. Accessibility of buildings to access roads.

2. Minimum intrusion into the site.

3. Not blocking the view towards Soltaniyeh dome and historical grassland.

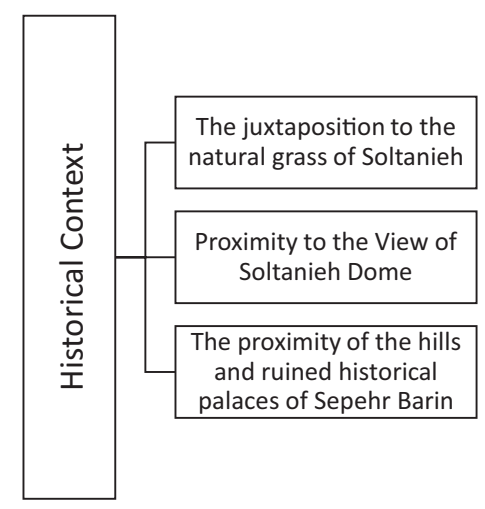

Figure 3. Monuments and historical sites adjacent to the design site

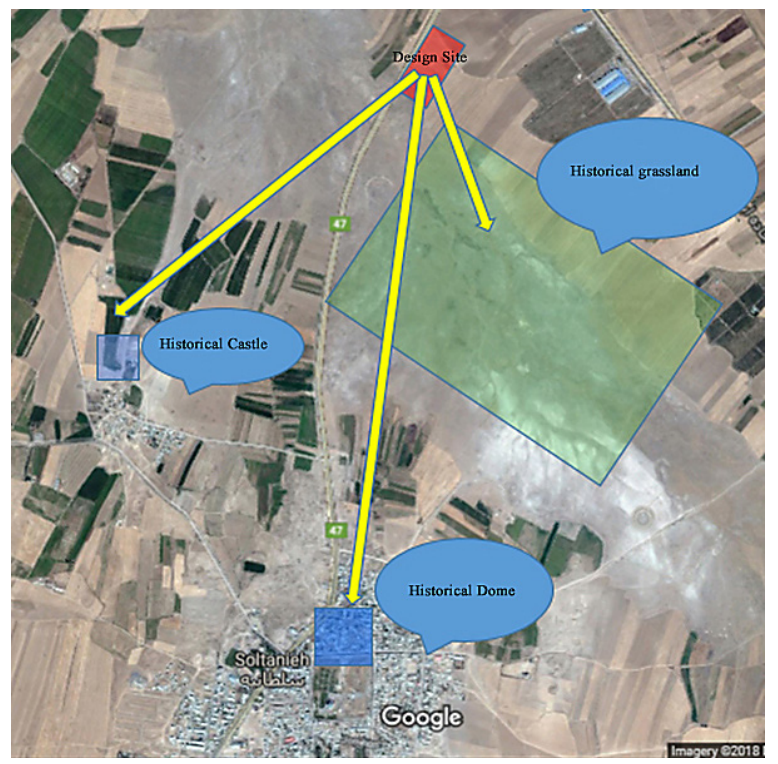

Figure 4. Monuments and historical sites adjacent to the design site

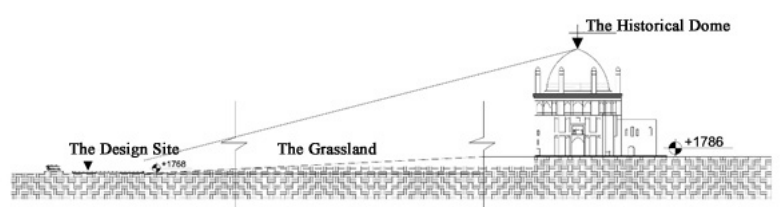

Figure 5. Mutual view of Soltaniyeh dome and site

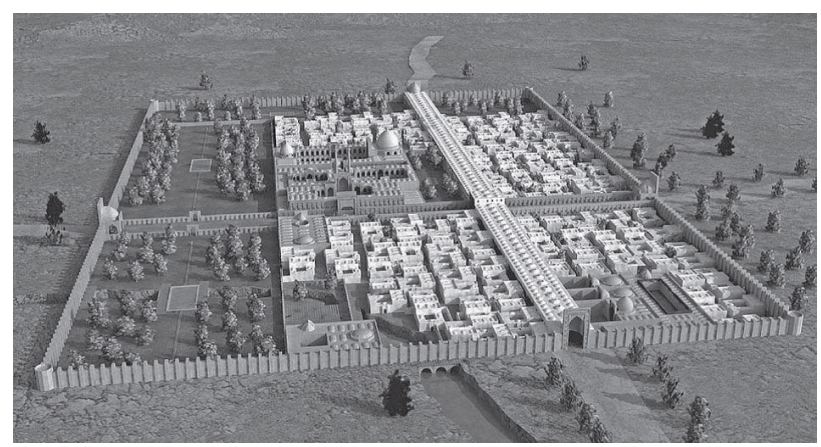

Figure 6. Rabe-Rashidi complex 


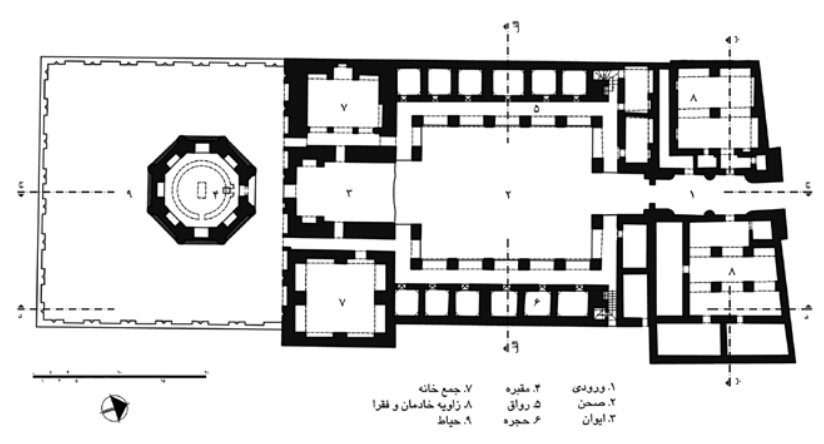

Figure 7. Four-part plan of Monastery of Chalabi Oghli

Therefore, the construction of the complex on the edge of the road and towards the access path by maintaining the approach of the dominant garden environment to the buildings of this complex.

\subsection{Cultural context}

Historic cities, especially small towns such as Soltaniyeh, have maintained their native culture throughout history. The development of sustainable tourism and the repetition of the number of trips cannot be achieved by visiting historical monuments. Indigenous activities and behavior generally give a positive collective memorial to the people, thus focusing on Soltaniya's unique cultural and native activities, such as medicinal plants growing in the Soltaniyeh climate, or traditional native and traditional therapies for sustainable tourism and repeat travel to this city is the cultural development of the complex.

The application of this important role in the form of cultural events has led to the survival of this activity and the recognition of these native activities. Therefore, the designation of architectural objects corresponding to these activities is the most important cultural characteristic in the field of design. But it should be noted that as much of a closed architectural space is important, the use of open space in the historical context is important. In the previous sections, one of the design approaches is the least physical design interference. Therefore, the open space of this complex is not merely green space or access space, and because for several years, the potential of holding the festival Different types has been created in Zanjan province.

Therefore, there is no concern about attracting tourists and introducing tourists to these festivals, and the provincial potential for local development is ultimately exploited. In the same vein, the open space of the exhibition, including the exhibition of medicinal herbs, is aimed at the presentation and display of indigenous and local products. The scientific significance of the existing buildings of the city of Soltaniyeh (Soltaniyeh Dynasty, Soltaniyeh Historical Center, Mullah Hassan Kashi monument, Chalabi-Oghli monastery) has led to a large number of tourists visiting the city of Soltaniyeh as domestic and foreign tourists. The existence of the National Congress Center, according to the General Director of the Cultural Heritage of Zanjan

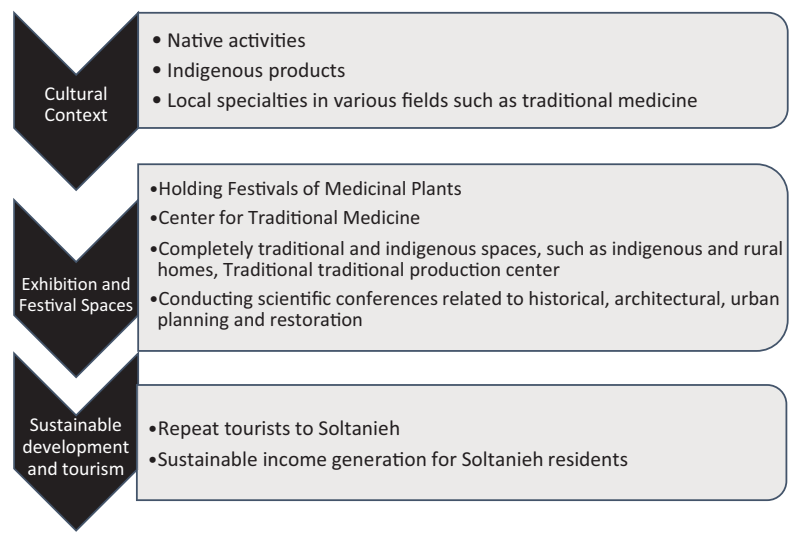

Figure 8. How to use cultural activities and their outcomes

Province, will be based on the needs of the province and the city of Soltaniyeh. In addition to meeting the local needs of the region, the cultural and educational function of the region will lead to serious scientific activities in the related areas to the historical monuments of Soltaniyeh. Matching the roles and functions of the tourism complex with the behavioral, ideological, and native culture is an important factor that leads to a two-way relationship between the tourist complexes and the people of that area to boost the complex. The hierarchy of cultural context and relative activities are shown in Figure 8. Therefore, as tourism complexes in small and especially historic cities, such as Soltaniyeh, conform to indigenous culture, it is also attractive to tourists in terms of indigenousness and, on the other hand, it will bring local people to support.

\subsection{Social context}

The development of small cities, especially small historical cities, is considered a national concern, which is often recommended to developing by the industrial process, which is mainly not conducive to sustainable development, and most of the non-indigenous people reside and work there. Sustainable development of small towns, especially small historical cities, has a direct relationship with the development of tourism infrastructure. In the previous sections, it was explained that the popular acceptance of constructed buildings in a context of historical context depends on the relation of that structure with the people of the city. Therefore, the elimination of social problems of people, such as unemployment by tourism complexes, reduces many social damages. This social relationship involves the use of people and their contribution to the profits of these sets. Architectural forecasting in proportion to the available capacities of small historical cities such as Soltaniyeh, such as the supply of indigenous handicrafts, the training, and utilization of indigenous people in health tourism sectors, the use of indigenous people in the service and shop departments of Rural homes, as well as the use of educated people in more specialized use such as hotel, this complex will reduce the city's unemployment rate and consequently the general acceptance of this complex in this 


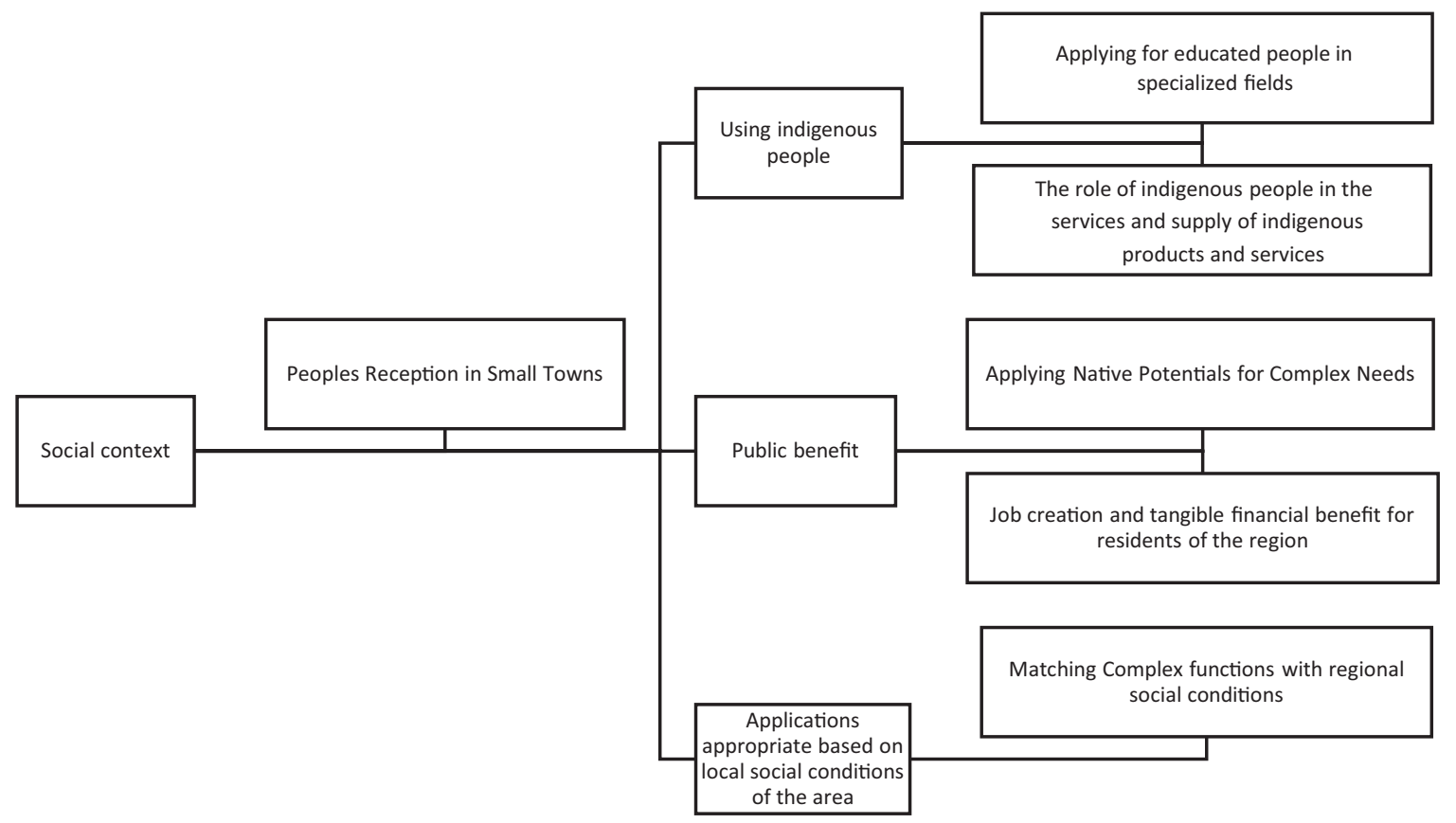

Figure 9. Social factors in the social context of the plan

historical context. The planning work-flow of social context is described in Figure 9. Therefore, the prediction of all functions related to sustainable tourism development and indigenous abilities of the region is one of the most important design concerns in the social scope of the plan.

\subsection{Natural context}

The natural landscape of Grassland of Soltaniyeh is one of the factors that is deeply influenced by architectural design. Ignoring the landscape of Soltaniyeh's grassland will cause a deficiency in the architectural designs of this complex. The green nature of this grass makes the greenery moves into the plan. This complex must be a green complex in terms of both nature and identity. Therefore, the concepts and structure of the four Persian gardens are more meaningful in terms of both visual and functional compatibility between the natural contexts and complex.

\subsection{Climatic context}

The climatic conditions in a macro-view look to the tourism complex in the climate and the open spaces adjacent to Greenland of Soltaniyeh, to provide the necessary facilities for the maximum comfort of the open space. In previous sections, the importance of the open spaces of this collection was cited in terms of culture, social and natural. Therefore, the necessary condition for the open space of this complex is the comfort conditions in terms of wind speed and amount of radiation. Since the environment is not enclosed and it is completely open, the profile of the wind becomes much more important. Control of wind speed and environmental comfort by planting trees is a solution that can control the wind speed in all directions and allow the environment to be radiantly attractive. As shown in the Figure 10, the picture of the wind profile of the region, the altitude, intensity, and time of wind speed increase as the altitude increases. Therefore, the overall attitude is lower in terms of the level of the planar level (which is normally 2.5 meters lower from the middle level of the region) and in terms of reducing the height of existing structures, the level of contact with the wind can be reduced in terms of time, intensity and speed. The major problem of planting green spaces and trees in this volume of the water problem is in the present era. Climatic sustainability strategies, as they have been able to solve such problems in many parts of the world, can also be used to raise the ecological level in open spaces of this complex. Storing rainwater according to what our predecessors were doing can be used to wastewater and storage for irrigation. Sewage treatment is also a solution recommended in many such complexes to avoid contamination of the surrounding environment and subterranean waters, as well as the water requirements of the complex in an abrasive crisis. The climatic sustainability of such complexes leads to long-term economic and operational efficiency and reduces the dependence of complexes on external factors and becomes more independent. How the climatic context affects the planning process is described in Figure 11. Open areas with natural substrates have a significant potential for using solar energy to generate electricity by solar panels and cells. The climate control strategies of the interior of the architectural functions require separate research on providing practical solutions for improving the climatic conditions of the interior spaces. 


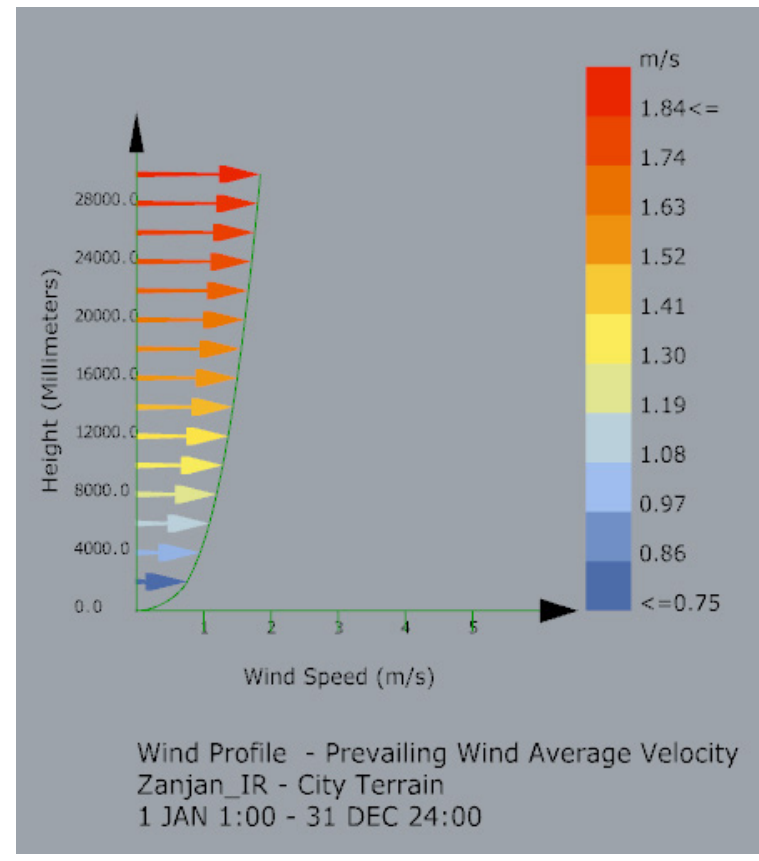

Figure 10. Soltaniyeh's wind profile

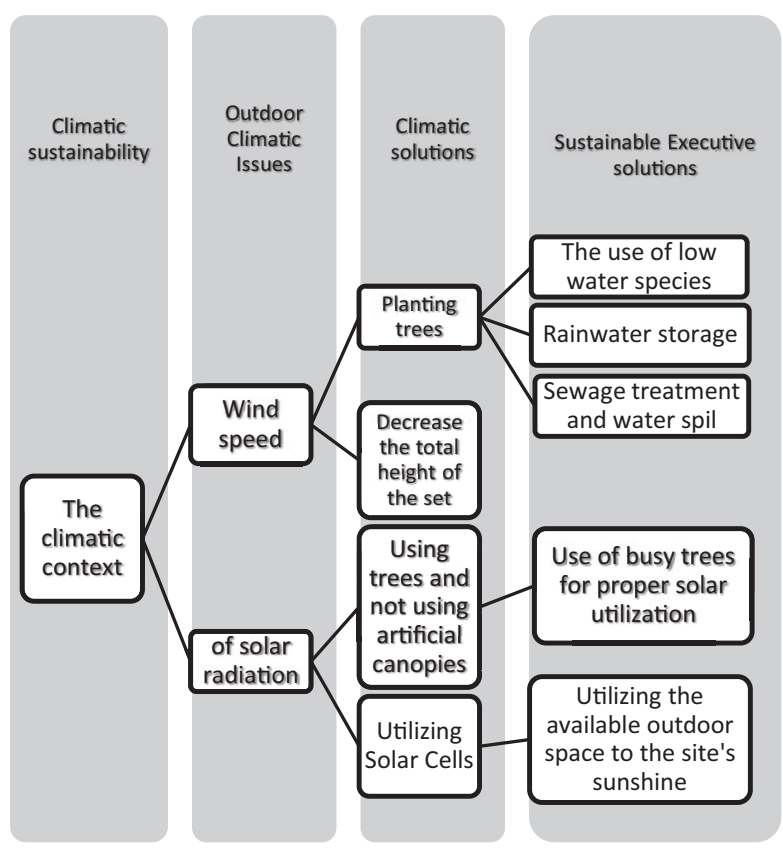

Figure 11. Climate conditions and solutions

\section{Final planning}

This section summarizes the topics discussed in the previous sections. In this research, the trend of designing and thinking of designing tourist complexes in small historical cities has been studied and it has been argued the integrated approach of context-oriented approach is the most suitable approach for designing in kind of cities. Therefore, the context-based state was studied according to the following list.

1. Historical context.

2. Cultural context.
3. Social context.

4. Natural context.

5. Climate context.

Considering what was discussed in various fields and aspects of design it is necessary to introduce the final architectural function following the 5 mentioned contexts. In the historical context as the final result and main guidelines that are provided for the designers. As functional results based on the existing historical accommodation buildings which historically belong to the architectural context therefore as the first assumption, the residential spaces can meet the historical requirements based on the described design principles in the Historical context's section. In the second section called Cultural context, it is mentioned that the designers should consider to the native activities which can come to true with activities based functions such as festival spaces, rural spaces based on vernacular patterns. When it comes to the social context as the third context, the main manifest of this section clarifies the circumstances of buildings in terms of the social benefits such as using the local and native workers and staff. Natural context plays an important role in the fourth step of contextual architecture as the practical result of this section using the vernacular potential of the architectural site which using the public spaces such as outdoor exhibitions and natural potentials such as herbal treatment can meet the natural context requirements. When it comes to the $5^{\text {th }}$ step namely climate context contribute to the quality of buildings in terms of climatic comfort and dominant features of environments context with software equipment can enhance the quality of outdoor activities with controlling environmental parameters such wind speed and solar exposure. Therefore as the final summary of the functional results of the study below list is described:

1. Historical context: using residential spaces.

2. Cultural context: using public spaces based on vernacular activities.

3. Social context: considering social benefits for all building.

4. Natural context: using exhibition spaces and herbals potentials.

5. Climate context: using software simulation reaching climatic comfort.

In the final step of these 6 functions are proposed as the main functions of this tourist complex in the historic city of Soltaniyeh based on the 5 mentioned contexts and functional results of the contexts

1. Using residential spaces: Hotel.

2. Using public spaces: National Conference Center.

3. Using exhibition spaces: Center for Therapeutic Tourism and Exhibitions and the cultivation of $\mathrm{Me}-$ dicinal Plants.

4. Using public spaces based on vernacular activities: Eco-camp and native-local houses.

5. Using exhibition spaces: Technological center and essential herbals oils of medicinal plants.

6. Using exhibition spaces: Healthy Traditional Medicine and Leech Training. 


\section{Conclusions}

Sustainable development has a wide-ranging and extensive meaning that is not generally addressed in real projects and planning in all its dimensions. Cities have been more industrialized in their development stages, and the concept of sustainable development has been further reduced to its climatic meaning and this is important damage that has affected most historic cities and this has intensified in small historic cities. In this research, various dimensions of sustainable development are extracted by the library research method and an attempt is made to use it in a real project in the historical city of Soltanieh and the integration is a method and the merit of the research. According to the literature review section, five contexts for sustainable development were identified, and such a comprehensive view is often not seen in current projects and designs. According to the results, the planning method is recommended for sustainable planning based on the mentioned contexts in the following chart:

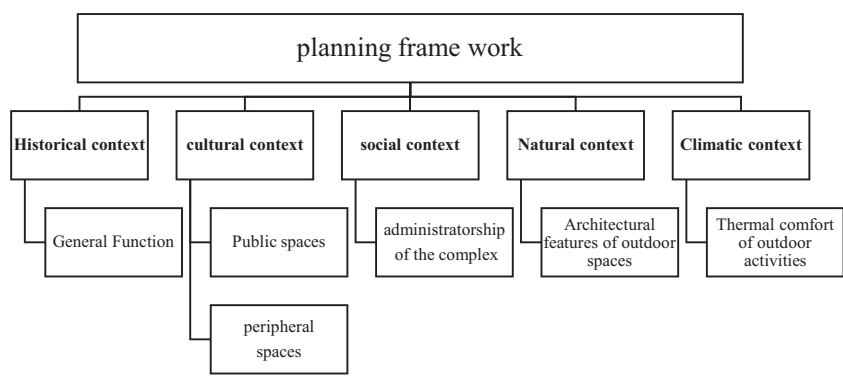

According to the results obtained from different parts, the following design and planning framework can be recommended as the main result of this research for the use of designers and architects for use in small historical cities (as a checklist):

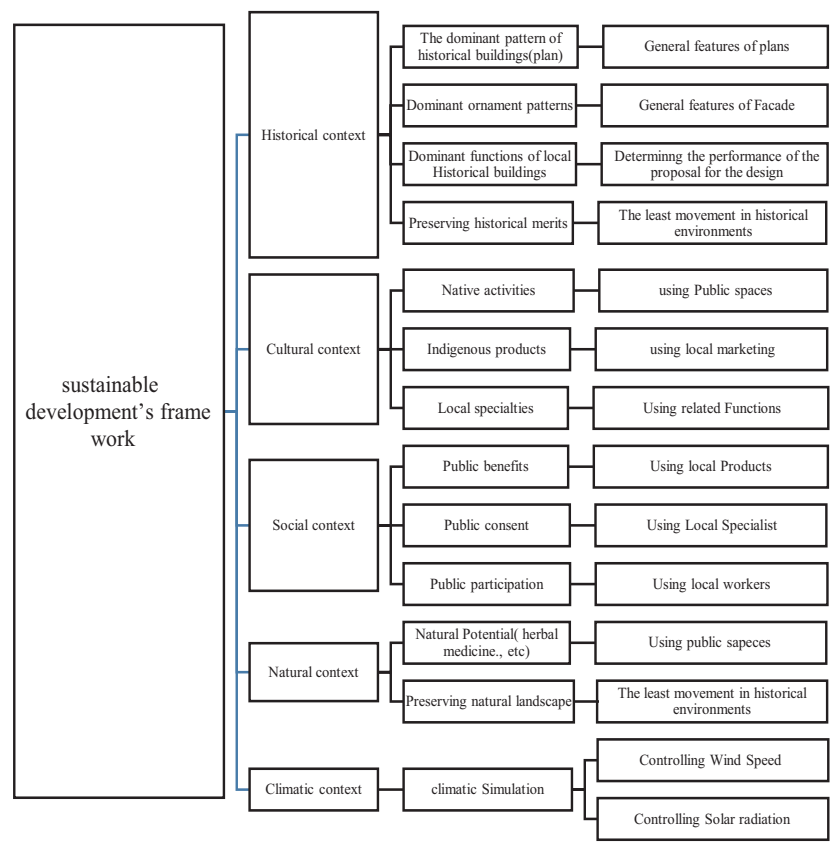

\section{Acknowledgments}

1. Special thanks to Mr. Ali Ghazanfarian, CEO of the Tarh, Azmon, Bana Consulting Engineers, for his spiritual supports and helpful guidance at various stages of the present research.

2. Many thanks to Mr. Amir Mofidi for providing the opportunity to carrying out the present research in the form of designing the Sepehr-e-Barin tourism complex in city of Soltaniyeh.Iran

\section{References}

Assari, A., Mahesh, T. M., Emtehani, M. R., \& Assari, E. (2011). Comparative sustainability of bazaar in Iranian traditional cities: Case studies in Isfahan and Tabriz. International Journal on Technical and Physical Problems of Engineering (IJTPE), 3(9), 18-24.

Abdollahzadeh, S. M., Erzhmand, M., \& Aminpour, A. (2013). Dimensions of social sustainability in the area of the traditional neighborhood of Iran, Case study: Sangh-Siah district of Shiraz. Architecture and Urban journal of Armanshahr, 10(19), 35-54.

Ahlfeldt, G., \& Wolfgang, M. (2009). Arenas, arena architecture and the impact on location desirability: the case of Olympic Arenas' in Prenzlauer Berg, Berlin. Urban Studies, 46(7), 1343-1362. https://doi.org/10.1177/0042098009104569

Andersen, B., \& Per, G. R. (2017). The social context and politics of large scale urban architecture: Investigating the design of Barcode, Oslo. European Urban and Regional Studies, 24(3), 304-317. https://doi.org/10.1177/0969776416643751

Attia, S., Gratia, E., De Herde, A., \& Hensen, J. L. (2012). Simulation-based decision support tool for early stages of zeroenergy building design. Energy and buildings, 49, 2-15. https://doi.org/10.1016/j.enbuild.2012.01.028

Bennetts, H., Antony, R., \& Terry, W. (2003). Understanding sustainable architecture. Taylor \& Francis. https://doi.org/10.4324/9780203217290

Bodach, S., Lang, W., \& Auer, T. (2016). Design guidelines for energy-efficient hotels in Nepal. International Journal of Sustainable Built Environment, 5(2), 411-434.

https://doi.org/10.1016/j.ijsbe.2016.05.008

Brundtland, G., Mansour, K., Susanna, A., Sali Al-Athel, B., Chidzero, L. F., \& Volker, H. (1987). Our common future ( 'brundtland reportl').

Cheng, T.-M., \& Homer, C. W. (2015). How do environmental knowledge, environmental sensitivity, and place attachment affect environmentally responsible behavior? An integrated approach for sustainable island tourism. Journal of Sustainable Tourism, 4, 557-576. https://doi.org/10.1080/09669582.2014.965177

Eleftheriadou, Z. (2010). Cross-cultural counselling psychology. In Handbook of counselling psychology. Sage.

Ferretti, V., Marta, B., \& Giulio, M. (2014). Decision making and cultural heritage: An application of the Multi-Attribute Value Theory for the reuse of historical buildings. Journal of Cultural Heritage, 15(6), 644-655.

https://doi.org/10.1016/j.culher.2013.12.007

García, O., \& Katarina, M. (2012). Definition of the procedure to determine the suitability and durability of an anti-graffiti product for application on cultural heritage porous materials. Journal of Cultural Heritage, 13, 77-82.

https://doi.org/10.1016/j.culher.2011.07.004 
Ghafourian, M., Seal Vahid, A., \& Nowruzadeh, Z. (2017). Recognition of the components of social sustainability affecting the increase of social interactions in residential complexes (Abazar neighborhood, Tehran). Urban Identity Journal, 11(30), 31-44.

Gharouri al-Khwansari, M. (2014). From the traditional neighborhood to the contemporary neighborhood; Conductivity in ways to revive local identity in today's city. Architectural Journal of Armanshahr, 60-76.

Harun, N. Z., Khalilah, Z., Mazlina, M., \& Khairunnisa, Z. (2014). Determining attributes of urban plaza for social sustainability. Procedia-Social and Behavioral Sciences, 153, 606-615. Springer. https://doi.org/10.1016/j.sbspro.2014.10.093

Hasehzadeh Haseh, R., Khakzand, M., \& Ojaghlou, M. (2018). Optimal thermal characteristics of the courtyard in the hot and arid climate of Isfahan. Buildings, 8(12), 166.

https://doi.org/10.3390/buildings8120166

Horlings, L. G. (2015). Values in place; a value-oriented approach toward sustainable place-shaping. Regional Studies, Regional Science, 1, 257-274.

https://doi.org/10.1080/21681376.2015.1014062

Kim, P. H., Donald, L. F., Cecily, D. C., \& Kurt, T. D. (2004). Removing the shadow of suspicion: the effects of apology versus denial for repairing competence-versus integrity-based trust violations. Journal of Applied Psychology, 89(1). https://doi.org/10.1037/0021-9010.89.1.104

Kirby, A. E., \& Antony, M. K. (2010). Architecture as brand: store design and brand identity. Journal of Product \& Brand Management, 19(6), 432-439. https://doi.org/10.1108/10610421011085749

Lele, S. M. (1991). Sustainable development: a critical review. World Development, 19(6), 607-621. https://doi.org/10.1016/0305-750X(91)90197-P

Levi, D. J. (2005). Does history matter? Perceptions and attitudes toward fake historic architecture and historic preservation. Journal of Architectural and Planning Research, 22(2), 148-159.

Li, F., Rusong, W., Juergen, P., \& Xusheng, L. (2005). Comprehensive concept planning of urban greening based on ecological principles: a case study in Beijing, China. Landscape and Urban Planning, 72(4), 325-336.

https://doi.org/10.1016/j.landurbplan.2004.04.002

Mitchell, G. (1996). Problems and fundamentals of sustainable development indicators. Sustainable Development, 4(1), 1-11. https://doi.org/10.1002/(SICI)1099-1719(199603)4:1<1::AIDSD24>3.0.CO;2-N

Ochoa, C. E., \& Capeluto, I. G. (2009). Advice tool for early design stages of intelligent facades based on energy and visual comfort approach. Energy and Buildings, 41(5), 480-488. https://doi.org/10.1016/j.enbuild.2008.11.015
Ojaghloo, M., \& Khakzand, M. (2019). Comparative study of shading effect of built environment on thermal comfort in two campuses of Tehran. Iran University of Science \& Technology, 29(1), 1-14.

Ojaghlou, M., \& GHasemlou, F. (2016). The role of accessibility of traditional neighborhoods in promoting the sense of belonging in traditional neighborhoods. Case study: Zanjan Green Square. Paper presented at the International Conference on Urban and Architectural Engineering, Tehran, Permanent Secretariat of the Conference. Civilica.

Ojaghlou, M., \& Khakzand, M. (2017). Cooling effect of shaded open spaces on long-term outdoor comfort by evaluation of UTCI Index in two Universities of Tehran. Space Ontology International Journal, 6(2), 9-26.

Ponzini, D. (2011). Large scale development projects and star architecture in the absence of democratic politics: The case of Abu Dhabi, UAE. Cities, 3, 251-259. https://doi.org/10.1016/j.cities.2011.02.002

Romero, D., Ovidiu, N., Johan, S., Peter, B., \& Åsa, F.-B. (2015). Towards a human-centred reference architecture for next generation balanced automation systems: human-automation symbiosis. In IFIP International Conference on Advances in Production Management Systems (pp. 556-566). Springer. https://doi.org/10.1007/978-3-319-22759-7_64

Salehi Milani, S., \& Mohammadi, M. (2010). Objectives and indices for the realization of cultural sustainability. Architectural and Urban Planning, 3(5), 81-98.

Sen, A. (2013). A survey of sustainable development:social and economic dimensions. Island Press.

Sharifi, A., \& Akito, M. (2016). Changes in the traditional urban form and the social sustainability of contemporary cities: A case study of Iranian cities. Habitat International, 38, 126-134. https://doi.org/10.1016/j.habitatint.2012.05.007

Vaqefi, E., \& Haghighatian, M. (2014). Investigating the impact of cultural capital (institutional dimension) on environmental social behaviors with sustainable urban development approach (Case study: Shiraz city). Quarterly Journal of Economics, 47-65.

Vard, M., Faizi, M., Khakzand, M., \& Ojaghlou, M. (2019). Thermal characteristic of open and semi-open spaces in the climatic conditions of Tehran. Journal of Architectural and Environmental Research, 1(2), 31-48.

$\mathrm{Xu}, \mathrm{Z}$., \& Jie, Z. (2016). Antecedents and consequences of place attachment: A comparison of Chinese and Western urban tourists in Hangzhou, China. Journal of Destination Marketing \& Management, 2, 86-96.

https://doi.org/10.1016/j.jdmm.2015.11.003

Zarghami, I. (2010). Principles of social stability of residential complexes in Iranian - Islamic cities. Islamic City Studies, 1(2), 103-115. 